\title{
MULTIMÍDIA E JOGOS PARA SENSIBILIZAR CRIANÇAS E CAPACITAR AGENTES DE EDUCAÇÃO PARA O TRÂNSITO
}

\author{
Luciana Pereira da Silva - EPTC - lpereira@eptc.prefpoa.com.br \\ Julio Cesar Moreira de Almeida - EPTC - jalmeida@eptc.prefpoa.com.br \\ Iaraci de Souza Silva - EPTC - isilva@eptc.prefpoa.com.br \\ Raymundo Carlos Machado Ferreira Filho - UFRGS - paka@ufrgs.br \\ Maria Isabel Timm - UFRGS - beta@ cesup.ufrgs.br \\ Fernando Schnaid - UFRGS - fernando@ufrgs.br
}

Resumo: $\mathrm{O}$ artigo tem como objetivo relatar as experiências vivenciadas pela equipe de criação e desenvolvimento de objetos educacionais da Assessoria de Educação para o Trânsito da EPTC - Empresa Pública de Transporte e Circulação, de Porto Alegre, para aprender a desenvolver e usar objetos educacionais na sua função. Pretende-se mostrar também como se deu o processo evolutivo dos integrantes da equipe, evidenciando que a equipe, formada por agentes de fiscalização de trânsito e transportes (em Porto Alegre, capital do estado do Rio Grande do Sul, esses profissionais são chamados popularmente “Azuizinhos", em função da cor de seu uniforme), responsáveis pela área educacional, aprendeu a compreender a linguagem, desenvolver e utilizar ferramentas tecnológicas e pedagógicas que serviram como base para o seu trabalho. A atividade ocorreu como parte de um projeto conjunto entre a EPTC e a Universidade Federal do Rio Grande do Sul, através do Programa de Pós-Graduação em Informática na Educação, implantado ao longo do ano de 2006. Também são apresentadas considerações a respeito da influência dos jogos na educação para o trânsito.

Palavras-chave: Educação para o Trânsito, Objetos Educacionais, Jogos Educativos

Abstract: This article presents experiences of a transit education and fiscalization agents team, to learn and develop learning objects to be used in their functions (they have "Little Blues" as nickname, due to the colour of their uniforms, and are part of a Transit Education Department, of the public company of transports and circulation - EPTC, in Porto Alegre, Brazil). Authors reports how the learning process evolved, within the group, showing up how the team learned to comprehend, develop, produce and use this technological and educational tools. The activity was part of a joint project between EPTC and Federal University of Rio Grande Sul (UFRGS), through the Pos-Graduation Program in Computer Science applied to Education (PGIE), during the year of 2006. It also presents considerations about the influence of games in the education for the transit.

Keywords: Education for City Transit, Learning Objects, Educational Games

\section{A Necessidade de Educar para o Trânsito de Forma Organizada}

As atividades de educação para o trânsito caracterizam uma das obrigações legais da EPTC, voltadas para garantir a segurança e a fluidez da mobilidade urbana. Um dos desafios desta área é o de dar apoio à chamada transversalização da educação para o trânsito junto às escolas, para que seus temas possam ser tratados através de todas as disciplinas. Para enfrentá-lo, buscou-se uma forma de estruturar e disseminar as informações que circulam dentro da empresa, sejam elas de caráter técnico - como a legislação, as estatísticas, o estudo de casos, etc. -, sejam de caráter prático, relacionadas 
às vivências dos agentes de fiscalização do trânsito, ao longo do cumprimento de sua função, colocando todas estas informações a serviço do apoio às atividades de educação e da civilidade no trânsito. A organização e disseminação de informações de natureza múltipla é um dos alicerces da atividade educacional, uma vez que qualquer ação, seja ela dos agentes, dos técnicos ou da direção da empresa, envolve a apresentação de idéias e conteúdos, de forma estruturada, dirigida a públicos e níveis específicos de entendimento.

Historicamente, na EPTC, foram desenvolvidos materiais de apoio à atividade educacional em formato convencional, como folders, cartilhas, lâminas, textos ou cartazes que foram utilizados para atividades variadas, sem que se constituísse, ao longo do tempo, um acervo a ser re-utilizado, atualizado e transformado em inteligência produzida pela empresa, seus técnicos, seus diretores e, no caso, seus agentes de fiscalização encarregados das atividades educacionais.

As novas tecnologias - em especial aquelas baseadas na informática, nas novas linguagens de mídia e estratégias didático-pedagógicas de abordagem interativa, como os softwares educacionais, os vídeos digitais e os sistemas em formato de jogo - foram a forma sugerida pelos pesquisadores que idealizaram o projeto, para ampliar a potencialidade das atividades de educação para o trânsito atualmente existentes.

O conjunto de mídias educacionais resultantes do trabalho de capacitação dos agentes constituiu a parte inicial de um acervo informatizado - nos moldes dos modernos sistemas de comunicação-educação, como repositório de objetos educacionais estruturados em termos de modularização e re-utilização dos materiais - o qual deverá ser associada a um banco de casos práticos, informação sobre legislação de trânsito, de engenharia de segurança da área e outros itens que deverão consolidar a oferta de recursos sobre os quais basear a formação do público interno e externo à EPTC. Além disso, a capacitação dos agentes e a estruturação do fruto de seu trabalho em acervo virtual, para acesso via Internet, constituem peça importante no processo de profissionalização do serviço público prestado pela empresa, que valoriza, assim, o conhecimento profissional de servidores do quadro permanente, contribuindo para a diminuição das interrupções de projeto, em caso de trocas político-administrativas e colocando-o a serviço da comunidade de Porto Alegre.

\section{A Assessoria de Educação para o Trânsito (ASSET) da EPTC}

A ASSET estruturou-se no quadro da EPTC em agosto de 2005, pautada pela necessidade de apoiar os educadores, como se referiu acima, na atividade de transversalização do tema da educação para o trânsito. A capacitação de seus integrantes para o planejamento, criação e uso de mídias informatizadas, como animações e jogos educacionais, representa uma parte do conjunto de instrumentos de apoio às atividades educativas da Assessoria, as quais são realizadas junto a escolas públicas, privadas, em ações diretas com a comunidade, em eventos públicos, junto a empresas, entre outras formas de atuação. Paralelamente com o processo de aprendizagem prática dos agentes, para o uso dos softwares de animação (inicialmente o software Power Point, e posteriormente o software Flash), foram realizadas atividades de identificação de casos reais, vivenciados por eles, na prática cotidiana de organizar o trânsito e garantir o fluxo e a segurança de condutores e pedestres. Foram estes casos reais, conscientizados ao longo de vários debates sobre as potencialidades de representação e uso pedagógico das novas tecnologias, que deram origem aos roteiros que vieram a constituir o processo (ainda em desenvolvimento) de aprendizagem para produção e uso. 
As primeiras atividades foram de sensibilização dos próprios agentes para o potencial da nova tecnologia. Para isso, lançaram-se à pesquisa de figuras na Internet e seu uso em lâminas de Power Point, as quais constituíram um primeiro contato com a tecnologia informatizada. A atividade deveria apoiar um recurso tradicionalmente utilizado pelo grupo, a chamada contação de histórias, através da qual as crianças escolhem figuras para descrever a situação geográfica do trajeto entre sua casa e a escola, para que, junto com o agente, possa identificar sinais de trânsito e situações de risco. $\mathrm{O}$ apoio do computador à contação foi a primeira situação de envolvimento direto dos agentes, com a nova tecnologia, que não fazia parte de sua cultura profissional (Figura 1).

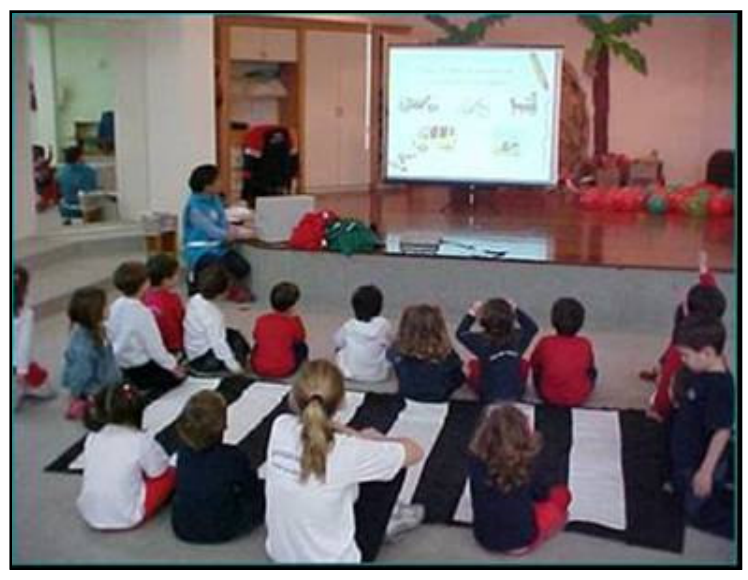

Figura 1: Contação de história com o uso de lâminas em Power Point

As atividades iniciais, de sensibilização e conhecimento das potencialidades das novas mídias, tiveram como objetivo - realizado, segundo seus relatos individuais levá-los a ganhar confiança no seu trabalho e a acreditar que tinham potencial para a produção de novas mídias educativas, uma vez que a cultura de uso de computadores, entre eles, era praticamente inexistente. Desde os primeiros encontros, foram incentivados a manter o contato direto e exploratório com as novas ferramentas, apropriando-se do seu funcionamento e criando objetos simples no intuito de garantir o entusiasmo e a persistência para a produção de objetos mais complexos.

É importante lembrar que no início da capacitação da equipe os agentes tinham muito claras as situações vivenciadas na prática, sem uma preocupação maior com a questão pedagógica , o que gerava uma certa ansiedade em expressá-las e utilizá-las junto ao púlico infantil. Ao longo da implantação do projeto, os agentes foram se familiarizando com os aspectos lúdico-pedagógicos, vendo a necessidade de se aproximar ao máximo da realidade da criança, através de linguagem adequada e com interface atraente, requisitos indispensáveis para que o objeto educacional tenha sucesso com este público alvo. Ressalte-se ainda que, dentro do grupo, procurou-se identificar capacidades específicas, para criar uma equipe com competência e agilidade para atividades diferenciadas. Este foi o caso do agente Júlio Almeida, que aprofundou sua capacitação com uso de softwares de desenho - Corell Draw - responsabilizando-se por suprir o grupo com figuras originais e cada vez mais complexas, para dar conta dos cenários dos jogos e das novas animações. Seu depoimento: "São surpreendentes suas aplicabilidades e suas ligeiras facilidades de assimilação, saudado com um bom retorno, tanto por educadores, quanto por educandos. Ao trabalhar com computação gráfica, especificamente o CorelDraw e o CorelTrace, passo a usar uma outra forma de 
linguagem. Desenvolvo outras habilidades artísticas e o gosto pela animação. A metodologia do desenho tradicional desdobra-se; a imagem sai do papel com o uso do lápis e ganha outra dimensão. Botar pensamentos em prática e ainda com um forte aspecto qualitativo das estruturas perceptuais, que ao serem lançados, os desenhos estáticos, ao programa flash são transformados, em animações, é incrível. Parece algo ejetável da tela (monitor) surgida de idéias, que ganham vida e comunicam-se com o público."

Foi o caso também da agente Iaraci de Souza e Silva, que desenvolveu extrema habilidade em produção de conjunto de lâminas em Power Point, para além da mera disposição de caixas de texto em slide, cujo depoimento de seu aprendizado dá conta de seu processo de aprendizagem: As lâminas "nos possibilitam o uso, não só de fotos de arquivos ou imagens da Internet, mas de programas, de filmes, músicas, etc. que podem ser animados e programados automaticamente, tornando assim, esse recurso visual mais atrativo, capaz de fixar a atenção e despertar o interesse dos mais diferentes públicos para o tema. (...). Sem apelações ou sensacionalismos, podemos montar uma apresentação que caracterize as emoções humanas ligadas ao comportamento juvenil. Portanto, é necessário entender que o processo de construção de uma apresentação em Power Point na Educação para o Trânsito deve objetivar a conscientização, a sensibilização, seja de crianças, jovens ou adultos, pois é através da interatividade deste recurso com seu público alvo, que compreendemos como interpretá-lo como um recurso que não se esgota em si, e sim como um veículo da mensagem a ser compreendida."

Antes de desenvolver as atividades educacionais, todos os integrantes do grupo desempenhavam a atividade convencional de fiscalização de trânsito, nas ruas de Porto Alegre, tempo em que, certamente, acumularam um conhecimento prático, vivenciado (e, por isso mesmo, fundamental), das situações de risco, específicas de cada local, cada área, cada idade e cada tipo de personagem do trânsito. Em função da importância da valorização desse conhecimento, paralelamente ao trabalho de exploração das ferramentas informatizadas, os agentes foram sendo estimulados a tomar consciência das possibilidades de expressar sua experiência de fiscalização do trânsito, através de múltiplas formas. Além das tecnologias informatizadas - objeto do projeto entre a EPTC e a UFRGS - também estruturaram um grupo de teatro, criaram folders, cartazes e outros instrumentos de divulgação dos cuidados no trânsito. No caso dos objetos educacionais, aprenderam a desenvolver roteiros para animações, os quais, em um primeiro momento, deram origem a produtos simples, onde a programação era realizada por bolsistas da Assessoria de Comunicação da EPTC, mas permitia que tomassem consciência do potencial das mídias, para expressar seu trabalho e consolidar sua relação com o público infantil. Na figura 2, exemplos destes primeiros trabalhos, cujos roteiros foram criados de histórias reais: alunos que atravessam a rua em frente à escola sem atenção; crianças sentadas no banco traseiro, sem cinto de segurança; crianças que correm atrás de bolas, com risco de atropelamento. Em todas as animações, a figura do mascote Azulito foi resgatada como elemento de apoio à aprendizagem, visando caracterizar a valorização de agente de fiscalização de trânsito e sua função de prestador de serviço profissional, para zelar pela segurança de motoristas e pedestres, juntamente com a ação educacional. 


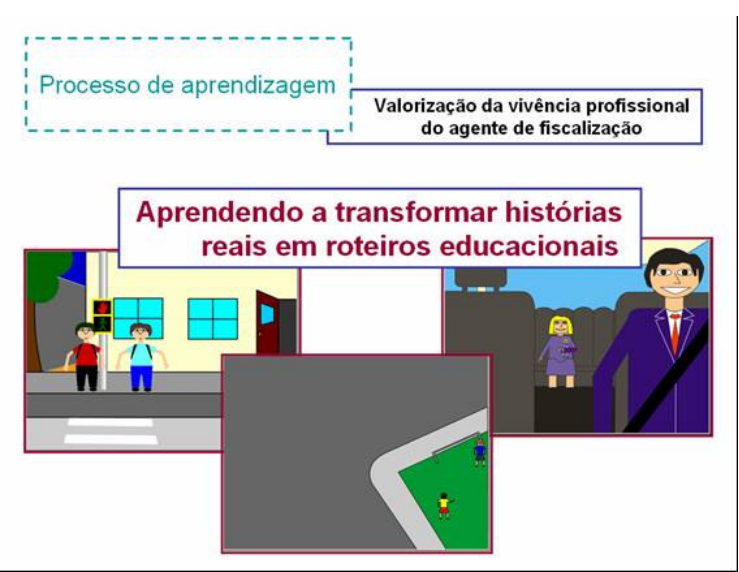

Figura 2: exemplo dos primeiros trabalhos desenvolvidos na ASSET

Do ponto de vista pedagógico, a capacitação dos agentes incluiu a realização de seminários sobre as possibilidades de uso das tecnologias educacionais, tanto quanto as necessidades pedagógicas de cada público. Procurou-se debater desde as características culturais onde ocorrem as situações de aprendizado em relação ao trânsito, até as necessidades de natureza biológica (percepção, atenção, entre outras) e a natureza cognitiva do aprendizado, responsáveis pela adesão dos futuros aprendizes, adultos e crianças, que serão objeto das ações dos agentes. Nesse sentido, caracteriza-se ainda a função de disseminadores das atividades pedagógicas, junto aos educadores da rede pública e privadas de ensino, em Porto Alegre, onde as ações transversais de educação para o trânsito são concretamente implantadas. Resultado dessa formação, que procurou valorizar conceitos teóricos, tanto quanto as aprendizagens ativas de produção de tecnologias, foram produzidas reflexões sobre o papel dos jogos educacionais na educação para o trânsito, cuja base será resumida a seguir.

\section{O papel dos jogos educacionais na educação para o trânsito}

A utilização de jogos na educação para o trânsito, quando bem conduzida, pode trazer inúmeras vantagens, pois possibilita que os conceitos de segurança sejam apresentados de maneira lúdica, auxiliando no treinamento de habilidades como coordenação motora, atenção, percepção, concentração e autonomia na resolução de problemas. $\mathrm{O}$ ato de jogar implica no reconhecimento de regras, saber interpretá-las e identificar o contexto onde estão situadas. Através dele, a criança tem a possibilidade de vivenciar situações cotidianas com liberdade e autonomia nas suas ações, preparando-se para enfrentar as adversidades da realidade em que vive. Entretanto, é preciso não superestimar o papel do jogo no desenvolvimento educacional da criança, pois, sem a presença de um mediador, os resultados podem não corresponder ao esperado. Neste ponto a questão da influência boa ou má dos jogos sobre as crianças ganha um outro viés, que é o de analisar não somente a influencia do jogo em si, mas o contexto sóciocultural em que estão inseridas - relações com a família, amigos, situação econômica que são tão ou mais importantes na sua conduta.

Ao analisar a influência dos jogos eletrônicos no comportamento das crianças, considera-se de extrema importância que os educadores estejam preparados para este fenômeno e, portanto, se apropriem das competências necessárias para utilizarem esta ferramenta no seu fazer pedagógico, de maneira que, aliando o ensino tradicional às novas tecnologias, ofereçam um ensino mais próximo do ideal. Respeitar e obedecer às regras do trânsito deve ser uma constante entre as pessoas, porém sabe-se que nem 
todos pensam dessa forma. Trabalhar estes conceitos desde a infância pode fazer com que os motoristas e pedestres do futuro sejam muito mais responsáveis. Com este intuito e baseados na grande influência que a informática tem sobre as crianças, iniciou-se o processo de criação das mídias, entre as quais estão os jogos, que vão servir de apoio ao projeto pedagógico da Assessoria de Educação para o Trânsito.

Murray (1997) descreve quatro características dos ambientes virtuais (a autora se refere aos jogos, mas aponta para características que podem ser comuns aos ambientes virtuais em geral): são procedurais (executam tarefas segundo regras, inferências, etc.); participatórios (usuários realizam neles seus desafios); espaciais (usuários são atores dentro da cena); e enciclopédicos (estão ligados a uma biblioteca universal exterior à memória humana), apontando para a importância de pesquisas relacionadas à potencialização de cada uma dessas características para o uso educacional. É inegável, nesse sentido, o universo de possibilidades educacionais abertas pelos computadores e seus desenvolvimentos através da multimídia, da Internet, das ferramentas de comunicação, dos bancos de informação, dos simuladores, das narrativas lúdicas, da sensibilização de emoções associadas às informações, da formação de comunidades, entre tantos outros impactos evidentes a uma simples observação.

Tentando-se explorar o potencial dos jogos virtuais, desenvolveram-se alguns roteiros de jogos para crianças. O resultado dos primeiros meses de trabalho foi o jogo do tipo arrastar-colar, "Monte o Azulito", uma espécie de quebra-cabeça do qual as crianças têm de recolocar as partes da roupa do mascote da EPTC no lugar correto. Esse jogo pretende aproximar a figura do agente de trânsito do público infantil, estabelecendo uma relação de confiança e afetividade. É importante salientar que ao criar esse vínculo com as crianças os agentes estão ganhando aliados na luta contra as transgressões ocorridas no trânsito, muitas vezes cometidas pelos próprios pais (Figura $3)$.

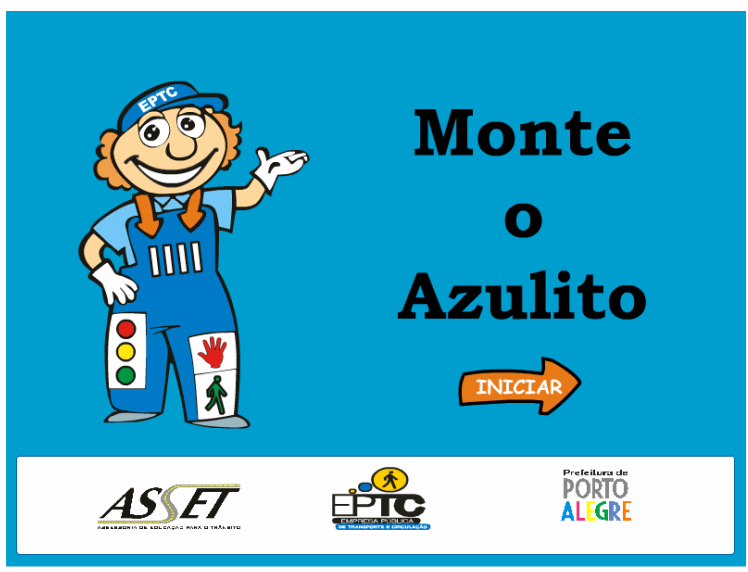

Figura 3: Tela de abertura do jogo Monte o Azulito

Outro exemplo de trabalho desenvolvido como parte da tomada de consciência sobre a função dos jogos foi o "Jogo da Memória" (Figura 4), que tem como objetivo desenvolver a atenção da criança, através da identificação dos pares de figuras iguais, apresentando os personagens do trânsito e fazendo a relação com a atenção que todos devem ter. Neste caso, buscou-se, através da função lúdica, explorar o desafio da criança de resolver o jogo da memória e encontrar, ao final de cada etapa, informações e sugestões de ações seguras no trânsito. Em particular, este jogo tem tido ótima aceitação 
das crianças, possivelmente porque vêem nele um exemplo de atividade conhecida de sua cultura presencial, o que remete para a necessidade de respeito à cultura de vida e de lazer dos educandos, para acessar suas expectativas e favorecer o aprendizado. $\mathrm{Na}$ Figura 5 tem-se exemplo de uso desse jogo, pelas crianças, em atividade da ASSET.

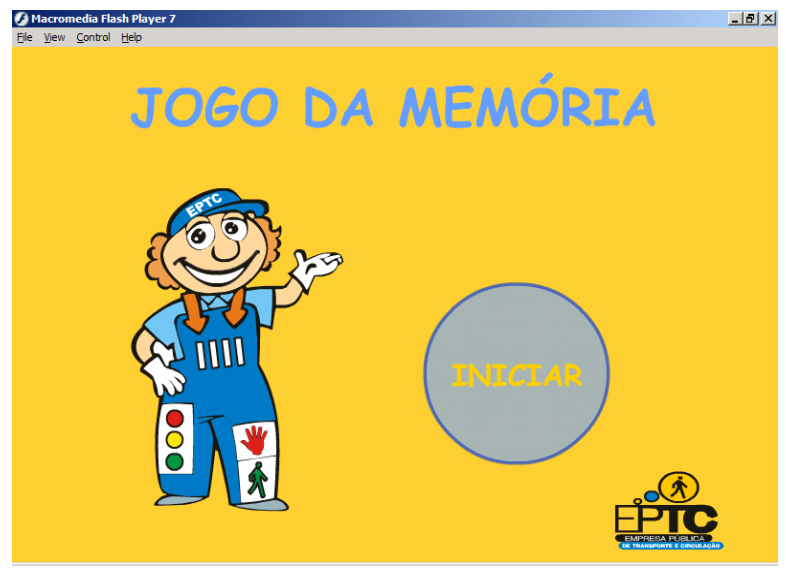

Figura 4: jogo de memória para identificação de sinais e situações de trânsito

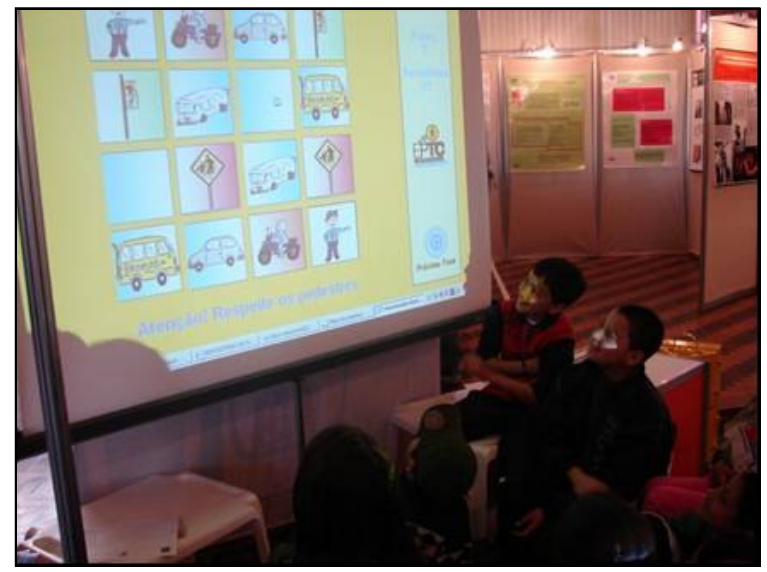

Figura 5: crianças usando o objeto educacional "Jogo da Memória"

Um outro jogo, que foi criado a partir da vivência prática dos agentes, é o Jogo das Perguntas. Esse jogo tem como objetivo apoiar as atividades dos professores após o contato das crianças com a peça de teatro Com licença, preciso passar! - que também foi criada e é encenada por agentes de trânsito do grupo Trilhas e Percalços da Assessoria de Educação para o Trânsito. O jogo consiste em apresentar perguntas sobre a peça com o intuito de avaliar o entendimento das lições, por parte das crianças, que são transmitidas ao longo da apresentação (Figura 6). 


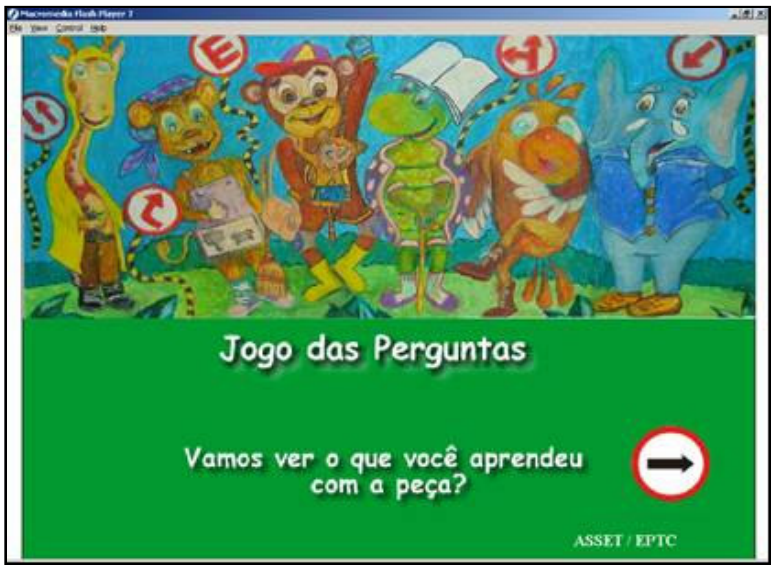

Figura 6: tela de abertura do Jogo das Perguntas

Além dos jogos, criou-se um conjunto de animações que pudessem ser utilizadas pelo professor/educador em sala de aula e que chamasse a atenção para situações de riscos no trânsito. Um dos roteiros desenvolvidos foi o da animação Um Dia no Trânsito, que além de ter como foco principal a travessia na faixa de segurança, chama a atenção para que a criança ande sempre segurando a mão de um adulto, mostra a diferença entre os dois tipos de semáforos e reforça a imagem do agente de trânsito através do Azulito. Duas outras animações, que fazem parte do conjunto de Um Dia no Trânsito, fazem referência a estacionar em fila dupla e a sentar no meio fio das calçadas (Figura 7), atitudes essas que são muito comuns no contexto escolar.

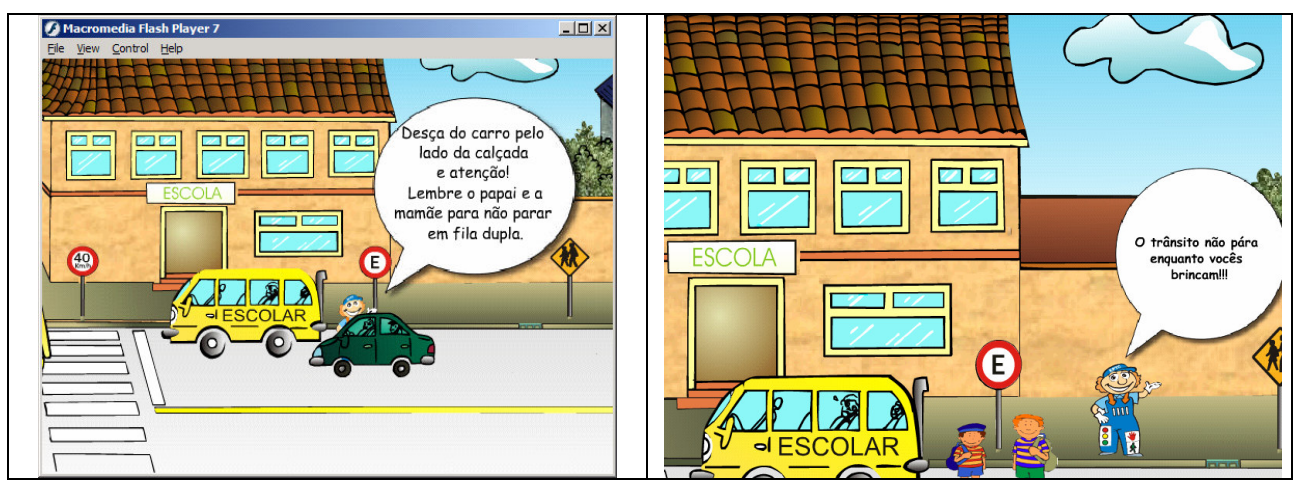

Figura 1: animação que aborda o estacionamento em fila dupla na frente de escolas e animação que alerta sobre o perigo de sentar ou estar próximodo meio-fio.

\section{Repositório de objetos educacionais para a educação no trânsito}

Atendendo-se à necessidade de re-utilização dos materiais produzidos, visando otimizar os recursos e, principalmente, torná-lo acessível via Internet, aos educadores da rede pública e privada de Porto Alegre, bem como de outros interessados no tema, no Brasil ou em outros países, foi desenvolvido um acervo, para indexação e busca dos objetos. O repositório de objetos educacionais está disponível na Internet e pode ser acessado pelo endereço eletrônico www.ufrgs.br/GPECT. Neste sistema encontram-se todos os materiais educacionais desenvolvidos na ASSET, os quais poderão ser utilizados por educadores em suas atividades . 
Este repositório de objetos educacionais seguiu as recomendações de implementação apresentadas por Ferreira Filho (2005). A estrutura de armazenamento e a modelagem de dados permitem que se realize, no repositório, buscas por uma taxionomia definida pelas grandes áreas de atuação da EPTC (Fiscalização de Trânsito, Engenharia de Trânsito e Educação para o Trânsito) e por suas sub-áreas, além de permitir buscas com filtros por tipo de mídia (imagem, animação, jogos, etc) ou palavrachave qualquer. O resultado da busca é uma lista dos objetos encontrados apresentados por uma descrição suscinta (Figura 8).

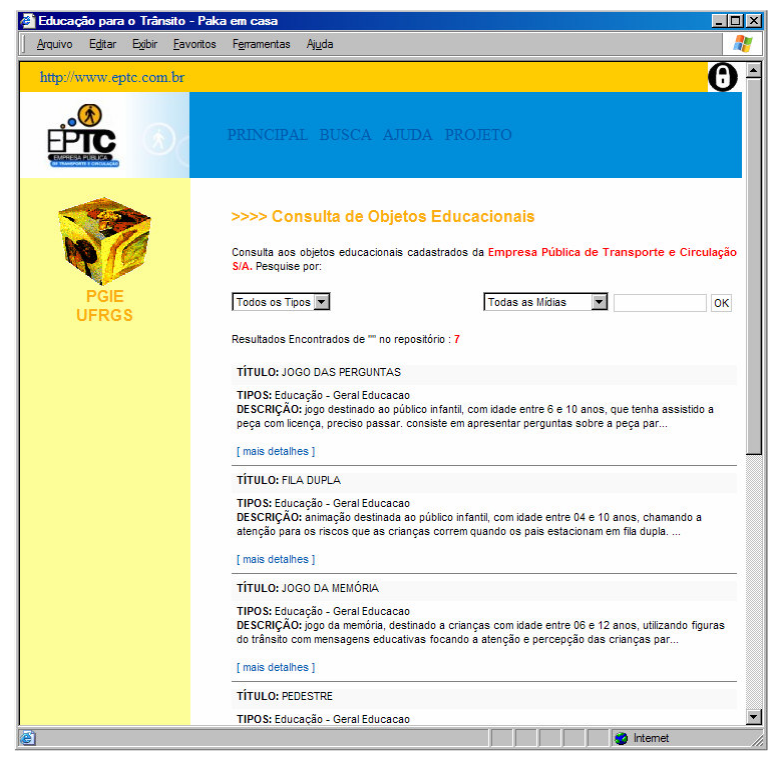

Figura 8: lista de registros encontrados para uma determinada busca realizada.

Ao clicar em mais detalhes, é possível ver a descrição completa do objeto, além de poder vizualizá-lo (Figura 9). Os metacampos de descrição dos objetos seguiram as recomendações do padrão Dublin Core (THE DUBLIN CORE METADATA INITIATIVE, 2006). O sistema de busca implementado, bem como a descrição dos objetos a partir do uso de um padrão internacional de catalogação de informações teve o objetivo de facilitar o acesso dos usuários aos objetos educacionais cadastrados no repositório.

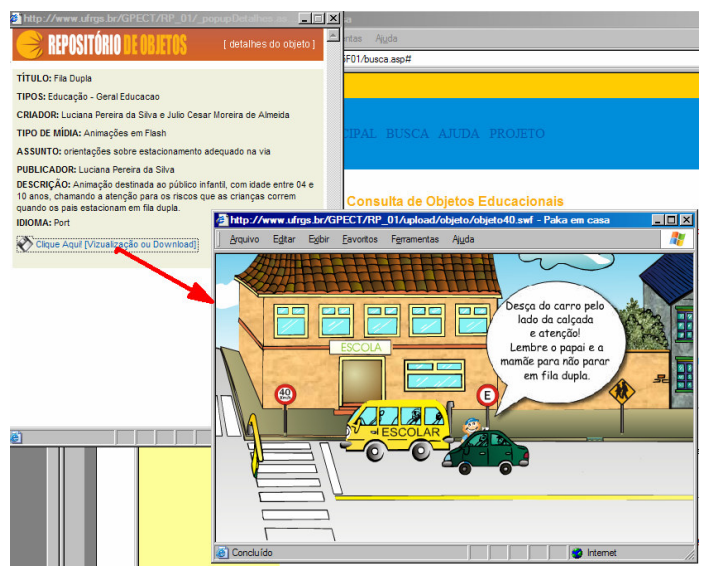


Figura 9: figura mostrando a tela de descrição de um objeto escolhido e a tela de visualização, sendo, no caso, uma animação que trata do estacionamento em fila dupla.

\section{Conclusões}

A estruturação desse Projeto foi uma das grandes conquistas da EPTC, principalmente para a Assessoria de Educação para o Trânsito, pois mostra uma nova visão da empresa com relação à utilização e inserção de novas tecnologias também na Educação para o Trânsito. Chama-se a atenção para a valorização dos saberes internos da empresa, neste caso, dos agentes de trânsito que participam do Projeto, haja vista que são servidores que pertencem ao quadro de funcionários da empresa e, portanto, representam o conhecimento que fica na empresa. Para os próprios agentes, é importante esse reconhecimento, pois fica visível o empenho que toda a equipe teve em aprender e estruturar formas atualizadas e diferenciadas de conhecimento para utilizar como ferramenta de trabalho. Espera-se que os objetos educacionais aqui mencionados possam cumprir o papel a que se destinaram, visto que é evidente a necessidade de criação de uma cultura de respeito e civilidade no trânsito, a qual permita que as relações estabelecidas no mesmo sejam mais humanas e seguras.

\section{Referências Bibliográficas}

ALAVA, S. et al. Ciberespaço e formações abertas: rumo a novas práticas educacionais?. Porto Alegre: Artmed, 2002.

ALMEIDA, G. C. P. Diversidade de mídias: procura do melhor aprendizado. Disponível em <http://www.geotecnia.ufjf.br/diversidade.pdf>. Acesso em Fev. de 2005.

CHEN, P. P. The entity-relationship model: toward a unified view of data. In: SPECIAL ISSUE: PAPERS FROM THE INTERNATIONAL CONFERENCE ON VERY LARGE DATA BASES, 1976, v.1, n.1, p.9-36. New York, NY, USA: ACM Press, 1976.

COOD, E. F. Extending the database relational model to capture more meaning. In: INTERNATIONAL CONFERENCE ON MANAGEMENT OF DATA, 1979, Boston Massachussets, USA. Proceedings, v.4, n.4, p.397-434. New York, NY, USA: ACM Press, 1979.

FERREIRA FILHO, R. C. M. Contribuições ao uso de Tecnologias da Informação e Comunicação no Ensino de Engenharia. Dissertação (mestrado). Programa de PósGraduação em Engenharia Civil. UFRGS. 2005.

MURRAY, J. Hamlet on the holodeck. New York, NY, USA: Free Press, 1997. THE DUBLIN CORE METADATA INITIATIVE. Making it easier to find information. Disponível em <dublincore.org>. Acessado em Novembro de 2006. 